\title{
UK hospital patient discharge: the patient perspective
}

\author{
Sally Wright, ${ }^{1}$ Charles W Morecroft, ${ }^{1}$ Rachel Mullen, ${ }^{1}$ Alison B Ewing ${ }^{2}$
}

\begin{abstract}
- Additional material is published online only. To view please visit the journal online (http://dx.doi.org/ 10.1136/ejhpharm-2016001134).
\end{abstract}

'School of Pharmacy and Biomolecular Sciences, Liverpool John Moores University, Liverpool, UK ${ }^{2}$ Pharmacy Department, The Royal Liverpool and Broadgreen University Hospital NHS Trust, Liverpool, UK

Correspondence to Sally Wright, ORCID ID: 0000 0002-0313-2274, School of Pharmacy and Biomolecular Sciences, Liverpool John Moores University, Room 7.46 James Parsons Building, Byrom Street, Liverpool L3 3AF, UK; s.bullock@2014.ljmu.ac.uk

Received 13 October 2016 Revised 8 December 2016 Accepted 12 December 2016 Published Online First 13 January 2017

EAHP Statement 6: Education and Research

\begin{abstract}
Objectives Hospital discharge is a complex process

that can result in errors and delays for patients, particularly around the supply of medicines and communication of information. To improve patient discharge, patient perspectives of the discharge service must be explored to determine where patients feel problems arise. This study aimed to explore inpatient perceptions and experiences of the current discharge process.

Methods This study involved questionnaires with patients at a large city-centre teaching hospital.

Results A total of 104 inpatients participated, 60\% $(n=62)$ were male with an average age of 55 (age range 19-93). Participants were from a range of medical, surgical and admissions wards. The majority, $71 \%$ of respondents $(n=74)$, took regular medicines, with $65 \%$ $(n=48)$ taking five or more medicines daily. Most patients, $89 \%(n=87)$, were satisfied with their hospital discharge but felt that it took too long. The perceived main cause of delay was waiting for medicines. Other highlighted issues included lack of counselling by pharmacists and the need for more patient involvement throughout the discharge process.

Conclusions This study showed that certain aspects of the discharge process need improving to provide safe, quality care for patients and improve patient experience of discharge. The findings from this study will inform the development of a new model of care for patient discharge from hospital.
\end{abstract}

\section{INTRODUCTION}

NHS England's mission is to secure high-quality care for all. ${ }^{1}$ High-quality care in the NHS is defined and measured by three components: clinical effectiveness, patient safety and patient experience. ${ }^{23}$ High-quality care has historically focused on ensuring clinical effectiveness and safety of service provision, but more recently focus has shifted to improving the patient experience. ${ }^{3-5}$ NHS England is involved in many programmes of work aiming to improve the patient experience. ${ }^{6}$ One example is the medicines optimisation programme, which involves ensuring that the right patients get the right choice of medicine, at the right time. ${ }^{7}$ By focusing on patients and their experiences, the programme aims to improve patient outcomes, quality and value from medicine use. ${ }^{7}$

Effectively managing the patient journey is crucial to improving the patient experience, ${ }^{8}$ and discharge from hospital back into the community is an important aspect of this. Hospital discharge is a complex process with many potential sources of error and delay, ${ }^{9}{ }^{10}$ particularly with regard to the supply of discharge medicines.

Research around patient perspectives of the discharge process is surprising; Horwitz found that patients reported a high level of satisfaction with discharge, despite evidence suggesting that patient care on discharge was inadequate. ${ }^{11}$ Similarly, the National NHS Inpatient Survey which assesses patient experience at hospitals across England ${ }^{11}$ showed that $84 \%$ of respondents rated their hospital experience as at least 7 out of 10, despite $42 \%$ of respondents' discharges being delayed. A large proportion $(61 \%)$ of those delayed discharges were perceived to be caused by waiting for medicines. ${ }^{12}$ These studies suggest that patients may not be aware of some of the internal problems that occur during discharge.

Patient involvement in their care is high on the government's agenda and thought to be important in improving patient outcomes. The government's aim is for all patients to be fully involved in decisions about their own care and that this becomes the norm across the NHS. ${ }^{12}$ Despite guidance advising that discharge planning should involve the patient, ${ }^{13-15}$ research has found that patient involvement appears to be limited during hospital discharge. ${ }^{9}$ Several studies have explored the reasons for low levels of patient participation at discharge. Patients cited the following reasons: many older people can be passive in relation to discharge planning, ${ }^{16}$ some people may be less assertive when they are ill $^{1617}$ and perceive their contribution to be unnecessary or not valued by their providers. ${ }^{18}$ Interestingly, one study suggests that healthcare providers' and patients' views differ on whether patients are involved. ${ }^{16}$

Patient involvement in their care is a major component of the medicines optimisation programme. ${ }^{19}$ In particular, good communication between healthcare professionals and patients is needed for involvement of patients in decisions about medicines and for supporting adherence. ${ }^{19}$ This communication with patients is key at discharge to support them with their medicines. One study showed that healthcare providers did not sufficiently prioritise discharge consultations with patients and family members due to time restraints and competing care obligations. ${ }^{20}$ Patient counselling is also thought to be limited at discharge. Some hospitals encourage patient counselling throughout the inpatient episode rather than at discharge. This could account for the perceived lack of counselling at discharge; however, the extent of inpatient counselling that occurs is also thought to be limited. ${ }^{9} 21$

Clearly, there is limited and conflicting evidence surrounding patient perspectives of hospital 
discharge, specifically relating to the supply of medicines at discharge. As a result, this descriptive study aims to bridge the current knowledge gap by exploring patient perspectives of the discharge process. This study follows on from the researcher's previous work, which explored the discharge process from the pharmacist perspective ${ }^{9}$ and focuses on medication supply at discharge as well as communication of information.

This research forms part of a larger project to develop a new model of care to improve patient discharge from hospital. The patient should be at the heart of all services within the NHS, ${ }^{1}{ }^{3} 22$ which is why patients' perspectives of the current service are essential to inform the new model of care.

\section{AIM}

This study aimed to explore patient perceptions and experiences of the current discharge process at the Royal Liverpool and Broadgreen University Hospital Trust (RLBUHT).

\section{METHOD}

This study consisted of a questionnaire-based survey to explore the current discharge process at the RLBUHT from the perspective of NHS patients. The study focused on the supply of discharge medicines and information provided to patients during their discharge. NHS research ethics committee $(15 / \mathrm{SC} / 0669)$ was obtained.

The RLBUHT is a large, multispecialty city-centre teaching hospital with a broad range of patients and approximately 110 discharges per day. Inclusion criteria for the study included ward-based inpatients (hereafter referred to as patients) ready for discharge to their usual place of residence, recruited from medical and surgical wards across the hospital. Exclusion criteria included patients with cognitive impairment unable to participate, along with those discharged to intermediate care, as this was considered an extension of their hospital admission. Patients discharged to new care homes were also excluded due to potential changes in their regular community-based care. Individual ward managers or the nurse-in-charge identified potential patient participants, who were then approached at their bedside by the researcher. Recruitment took place on the day of the patient's discharge so they had a clear recollection of their experience. Questionnaires were left with participants to complete and collected by the researcher after a mutually agreed period of time.

The questionnaire (see online supplementary file) contained 20 questions, consisting of mainly closed questions with a tick-box format for ease of use for participants. The questions were developed based on relevant existing validated questionnaires ${ }^{11}$ and the researcher's knowledge of the discharge process from a previous study. ${ }^{9}$ The questions covered a range of topics relating to different aspects of discharge. There were four main areas: patient perceptions of discharge, patient suggestions for improving the process and patient views on both their involvement during discharge and any counselling they received. The latter two areas of interest stemmed from a previous study highlighting that both patient involvement and patient counselling are issues within the discharge process. ${ }^{9}$

The time taken to complete the questionnaire ranged between 5 and 20 minutes depending on the individual participants and circumstances. Data collection took place on different days of the week including weekends during the period from 30 November 2015 to 7 February 2016.

Descriptive statistics were generated from the data using SPSS V.22. Several of the open-ended questions resulted in the collection of free text data which was used to contextualise the findings.

A pilot study was undertaken with four patients prior to commencing data collection. This verified the recruitment procedure, evaluated the questionnaire and developed the researcher's data entry and data analysis skills. These data were included in the main study as only minor amendments were made to the questionnaire.

\section{RESULTS}

\section{Demographic data}

All 104 patients approached, agreed to participate $(100 \%$ return rate). However, response rates to individual questions varied as not every participant answered all questions. Individual response rates are listed throughout the results tables. The demographic characteristics of the study sample are shown in table 1 .

The majority of participants $(71 \%)$ were taking regular medicines prior to admission to hospital. Of the patients taking regular medicines, $65 \%$ were taking five or more daily.

\section{Patient perceptions of the discharge experience}

Of the 98 participants who responded to the question concerning perceptions of discharge, most found that their discharge experience was either good $(57 \%, n=56)$ or satisfactory $(32 \%$, $\mathrm{n}=31)$, with the remaining $(11 \%, \mathrm{n}=11)$ rating discharge as poor.

Participants provided additional information regarding the positive and negative aspects of their discharge experience. While some participants commented that their discharge had been well organised with helpful staff, other participants noted several problems, most commonly 'it takes too long'. Individual examples of issues included one patient's regular medicines were forgotten until the last minute, which delayed their discharge. In another case, a bed was given to another patient while that patient was still awaiting discharge, much to the embarrassment of the ward staff.

Table 2 details the perceived reasons for delays to discharge. Participants were able to select more than one option if they felt that applied to their situation.

As can be seen in table 2, the most commonly perceived reason for a delayed discharge was waiting for medicines $(70 \%)$. Participants that selected 'other' reasons $(n=6)$ cited arrangement of follow-up care or awaiting further review by another healthcare professional prior to discharge.

Table 1 Demographic characteristics of study sample

\begin{tabular}{lc}
\hline & Response \\
\hline Age in years, mean (SD) & $55(18)$ \\
& $\mathrm{n}(\%)$ \\
Gender $(\mathrm{n}=104)$ & \\
$\quad$ Male & $62(60)$ \\
Female & $42(40)$ \\
Did patient take regular medicines? ( $\mathrm{n}=104)$ & \\
$\quad$ Yes & $74(71)$ \\
No & $30(29)$ \\
Number of regular medicines taken daily $(\mathrm{n}=74)$ & \\
$1-4$ & $24(32)$ \\
$5-9$ & $32(43)$ \\
$10+$ & $16(22)$ \\
Do not know & $2(3)$ \\
\hline
\end{tabular}


Table 2 Perceived reasons for delays to discharge

\begin{tabular}{lc}
\hline & $\begin{array}{l}\text { Response } \\
\mathbf{n}(\%)^{*}\end{array}$ \\
\hline $\begin{array}{l}\text { Perceived factors causing delay to patient discharge }(\mathrm{n}=92) \\
\text { Waiting for discharge medicines }\end{array}$ & $64(70)$ \\
Waiting for test results & $13(14)$ \\
Waiting for further tests & $9(10)$ \\
Waiting for transport home & $9(10)$ \\
Unsure & $6(7)$ \\
Other & $6(7)$ \\
Waiting for social care arrangements & $2(2)$ \\
\hline${ }^{*}$ Categories not mutually exclusive. &
\end{tabular}

Participants were asked how involved they felt in their discharge, as well as their understanding of the discharge process. Responses are reported in table 3.

Only $63 \%$ of participants felt that they had been involved in their discharge. Several patients commented that they felt they were sent home too early. One respondent in particular had mixed messages from different doctors about whether they were medically fit to go home which caused some anxiety.

The discharge process was explained to $74 \%$ of participants and $79 \%$ of participants felt that they understood the discharge process. However, only $57 \%$ felt that they were updated with the progress of their discharge.

\section{Patient counselling at discharge}

Participants were asked if any changes to their regular medicines during their hospital admission were verbally discussed with them. If changes had been discussed, participants were then

Table 3 Patient understanding and involvement at discharge

\begin{tabular}{|c|c|}
\hline & $\begin{array}{l}\text { Response } \\
\text { n (\%) }\end{array}$ \\
\hline \multicolumn{2}{|c|}{ Patient involvement in discharge process $(n=92)$} \\
\hline Strongly agree & $20(22)$ \\
\hline Agree & $38(41)$ \\
\hline Neutral & $12(13)$ \\
\hline Disagree & $10(11)$ \\
\hline Strongly disagree & $12(13)$ \\
\hline \multicolumn{2}{|c|}{ Was the discharge process explained to patients? $(n=95)$} \\
\hline Strongly agree & $24(25)$ \\
\hline Agree & $46(49)$ \\
\hline Neutral & $17(18)$ \\
\hline Disagree & $6(6)$ \\
\hline Strongly disagree & $2(2)$ \\
\hline \multicolumn{2}{|c|}{ Did patients understand the discharge process? $(n=94)$} \\
\hline Strongly agree & $32(34)$ \\
\hline Agree & $42(45)$ \\
\hline Neutral & $14(15)$ \\
\hline Disagree & $2(2)$ \\
\hline Strongly disagree & $4(4)$ \\
\hline \multicolumn{2}{|c|}{ Was patient updated on progress of discharge? $(n=94)$} \\
\hline Strongly agree & $20(21)$ \\
\hline Agree & $34(36)$ \\
\hline Neutral & $30(32)$ \\
\hline Disagree & $8(9)$ \\
\hline Strongly disagree & $2(2)$ \\
\hline
\end{tabular}

Table 4 Changes to regular medicines during admission

n (\%)

Changes to medicines during admission $(n=100)$

No changes to medicines

56 (56)

Changes to medicines 32 (32)

Patient did not know 12 (12)

Was patient clear about what medicines to take after discharge? $(n=32)$

Fully

$20(63)$

Partly

Not at all

asked if they understood what medicines they should be taking after discharge. Participant responses are shown in table 4.

The majority $(88 \%)$ of participants were aware if any changes had been made to their regular medicines during their hospital admission.

Participants were questioned about counselling they had or had not received about their medicines and which member of staff had discussed their medicines with them. These questions were directed at participants with changes to their regular medicines. Although not all 32 responded to every question, responses can be seen in table 5 along with the number of respondents.

Of the patients with changes to their medicines, the majority were told what their new medicine was for $(89 \%)$ and how to use their medicines (93\%). An important finding is that not all of the counselling points listed in table 5 were routinely covered with patients. Interestingly, according to participants only $13 \%$ of patient counselling was by a pharmacist.

\section{Patient suggestions for improvement of the discharge process}

Respondents were asked if the process of supplying discharge medicines could be improved and if so, how. Responses are given in table 6 . Table 6 also includes respondents' views on whether hospital staff could help patients with their medicines after discharge.

Less than one quarter (23\%) of participants felt that the service of supplying their discharge medicines could be

Table 5 Patient counselling for new medicines

\begin{tabular}{lc}
\hline & $\mathbf{n}(\%)$ \\
\hline Patient received counselling on the following points & \\
How to use the medicine(s) $(\mathrm{n}=27)$ & $25(93)$ \\
What new medicine(s) are for $(\mathrm{n}=27)$ & $24(89)$ \\
Benefits of new medicine(s) $(\mathrm{n}=26)$ & $23(88)$ \\
When to use the medicine(s) $(\mathrm{n}=26)$ & $22(85)$ \\
Whether further supplies are needed ( $\mathrm{n}=26)$ & $19(73)$ \\
How to obtain further supplies ( $\mathrm{n}=26)$ & $15(58)$ \\
Side effects of medicine(s) ( $\mathrm{n}=26)$ & $15(58)$ \\
Healthcare professional patient was counselled by ( $\mathrm{n}=32)$ & $\mathrm{n}(\%)$ \\
Consultant & $15(47)$ \\
Nurse & $11(34)$ \\
Other doctor & $9(28)$ \\
Pharmacist & $4(13)$ \\
No one & $2(6)$ \\
Do not know & $1(3)$ \\
\hline *Categories not mutually exclusive.
\end{tabular}


Table 6 Patient suggestions for improvement of discharge

n (\%)

Could the supply of discharge medicines be improved? ( $n=91)$
No

Do not know

Yes

Could the hospital help patients with their medicines after discharge? ( $n=96)$

No

Do not know

Yes

29 (32)

$21(23)$

$69(72)$

$20(21)$

7 (7) improved. These participants made suggestions for improvement of the service and responses included improving speed and communication, as well as having the option of collecting discharge medicines from an outside pharmacy to save time. One participant suggested that a community-based EMIS (EMIS Web is commercial software available in some hospitals and GP surgeries) collaboration to organise the prescription could be helpful.

Most participants (93\%) felt that hospital staff could not support them with their medicines after discharge, with one participant commenting 'people in the community should help me, it should be my general practitioner (GP) in charge'.

\section{DISCUSSION}

\section{Patient perceptions of discharge}

The findings indicate that a surprisingly high number of patients were satisfied with their experience, while still encountering issues during discharge. This study supports previous research where patients have reported a high level of satisfaction with discharge. ${ }^{11} 12$ There could be many reasons for this. It could be argued that patients' low expectations of hospital discharge are responsible for them reporting a high level of satisfaction with the discharge process despite known problems. Equally, the very fact the patient is being discharged could have resulted in a more positive response. Despite the majority of patients finding their discharge experience at least satisfactory, there is much room for improvement, as over two-fifths of patients found the experience 'poor' or only 'satisfactory' which is unacceptable.

Patients commonly felt that discharge from hospital took too long. Unfortunately, waiting for pharmacy to supply discharge medicines is commonly perceived by hospital staff as the main delay to discharge. ${ }^{23}$ This study suggests that patients also hold this view. This belief may stem from either real or perceived pharmacy-related delays. Real, for example, if pharmacists are unavailable to authorise discharge prescriptions, or discharge medicines take a long time to arrive from pharmacy. Perceived pharmacy-related delays could be through misinformation supplied by ward staff, or because the discharge process and its expected duration are not explained to patients. Previous research has shown that discharge delays are a much wider issue and pharmacy is not the only cause. ${ }^{923}$ Regardless of where the responsibility lies, the wait for medicines needs addressing to reduce the delay for patients and improve their experience.

\section{Patient suggestions for improving discharge}

Less than a quarter of patients felt that their discharge could be improved. This correlates with the findings that the majority of patients are satisfied with their discharge. Providing a faster service was the most common suggestion for improvement.
The findings suggest that community healthcare providers should support patients with their medicines after discharge, rather than hospital staff. It is interesting that patients see their GP as the main source of help with medicines after discharge. This could be due to a lack of awareness of the support available from community pharmacies who offer the New Medicine Service and Medicines Use Reviews to support patients recently discharged from hospital. Hospital pharmacists have an important role in signposting or referring patients to community pharmacies for support with their medicines.

\section{Patient involvement at discharge}

The findings for patient involvement at discharge are lower than national figures. The National Inpatient Survey 2014 found that $54 \%$ of patients strongly agreed that they were involved in decisions about their discharge, ${ }^{11}$ compared with only $22 \%$ in this study, demonstrating room for improvement. Although respondents were similar in age and gender, the variation could be due to the slight difference in how the questions were asked in both questionnaires and the much larger sample size in the national survey.

As previously mentioned, providing patients with the information required to enable involvement in their care is a government priority. ${ }^{12} 19$ The findings indicate that information about discharge was given to most patients. Nonetheless, all patients should be involved in their care and should therefore receive information about discharge. Explaining the complexities of the discharge process so that patients understand the numerous steps that need to take place before they are discharged would empower the patient and improve their experience. This includes regular accurate information about the duration of any delays during episodes of care. $^{24}$ Owing to the discharge process being a time consuming and complex one, inevitably delays can occur. Providing updates if discharge is delayed or if any changes occur will help the patient to understand what is happening and improve their overall experience.

\section{Patient counselling at discharge}

A component of the medicines optimisation programme is to support medicines adherence ${ }^{19}$ by providing patients with information about medicines. As it is estimated that between 30\% and $50 \%$ of patients do not take their medicines as intended, ${ }^{19}$ improving medicines adherence is vital. The majority of patients in the study stated that they were aware of changes made to their medicines during their admission. However, over a third of patients were unclear about what medicines they should be taking after discharge. This could be due to a lack of patient counselling, poor understanding of information or the patient not remembering information. It does highlight that improved communication of information is required and calls into question the quality of information given to patients and whether it is provided at an appropriate time.

Interestingly, findings indicate that pharmacists are the least likely healthcare professional to provide patient counselling, despite perhaps being the most appropriately trained in medicines use. This supports previous evidence that hospital pharmacists are unlikely to be providing adequate patient counselling. ${ }^{9} 21$

\section{Further work}

The study has successfully identified areas for improvement in the current discharge process. These findings will be used to inform the development of a new model of care for patient discharge in further work. This new model will rebuild the discharge process by drawing on elements that work well and 
redesigning ineffective parts of the process, as identified in this study.

\section{LIMITATIONS AND FURTHER WORK}

Recruitment for this study proved more difficult than anticipated with the main reason being the threat of junior doctors' strikes during the data collection period. Standard processes were altered during this period to ensure that patient safety was not compromised. This was not a true representation of the current discharge process and therefore data collection was interrupted.

In all questionnaires, there is a risk that participants may be reluctant to give honest answers to questions. However, the topic of discharge was not thought to affect participant responses. Nevertheless, participants were made aware that any information provided was confidential and anonymous. Not all participants answered every question, which may have led to response bias for individual questions. It was not possible to ascertain whether all possible patients were approached to participate because appropriate patients were referred by individual ward gatekeepers. This may have also caused response bias. As the study was specific to one hospital, the findings are not generalisable to other hospitals.

This study forms part of a larger research project and the findings will help inform the development of a new model of care for patient discharge from hospital back into the community, improving quality of care across the interface.

\section{CONCLUSION}

By assessing patient experience, this research has identified that despite the majority of patients feeling satisfied with their hospital discharge, issues commonly arise. Furthermore, the study has highlighted several areas that require improvement to provide safe, quality care for patients and improve patient experience at discharge.

The study builds on the existing knowledge of problems at discharge by adding the patients' perspective to issues commonly highlighted by healthcare staff. The findings support previous research which suggested that both patient counselling by pharmacists and patient involvement in discharge are limited. ${ }^{9}$ Findings also show that patients hold the same view as healthcare staff that discharge takes too long and is largely perceived to be due to the wait for discharge medicines. ${ }^{9} 23$

The study findings are invaluable to inform the development of a new model of care for patient discharge. The new model

\section{What this paper adds}

\section{What is already known on this subject?}

- Medication problems for patients after hospital discharge are well documented and can result in patient harm and hospital readmissions.

- It is important to determine the patient perspective of hospital discharge to improve patient discharge.

\section{What this study adds?}

- Despite the majority of patients claiming that they were satisfied with their hospital discharge, on further questioning they received less than optimal care.

- The discharge process needs improving to provide safe, quality care, and to improve patient experience the findings will inform the development of a new model of care for patient discharge from hospital. will include discharge medicines counselling provided by trained pharmacy staff as standard, support with medicines after discharge by community pharmacists, communication of information during discharge to all patients and preventing the wait for discharge medicines delaying patient discharge.

Contributors The study was carried out and this manuscript written by the main author SW as part of her PhD study. Support and guidance throughout the study and writing of the manuscript were provided by the supervisory team: CWM, RM and $A B E$.

Competing interests None declared.

Ethics approval NHS South Central—Berkshire B Research Ethics Committee. Provenance and peer review Not commissioned; externally peer reviewed.

\section{REFERENCES}

1 NHS England. Putting patients first, NHS England business plan 2013/2014-2014/ 2015. NHS England, 2013.

2 NHS England. NHS England our work. 2016 (cited 26 May 2016). https://www. england.nhs.uk/ourwork/pe/

3 Department of Health. The NHS constitution: the NHS belongs to us all. The Stationery Office 2015:1-16.

4 Darzi A. High quality care for all: NHS next stage review final report. London, The Stationery Office, 2008.

5 Department of Health. Equity and excellence: liberating the NHS (White Paper). The Stationery Office, 2010.

6 NHS England. Improving patient experience. 2016 (cited 26 May 2016). https:// www.england.nhs.uk/ourwork/pe/

7 NHS England. Medicines Optimisation Dashboard (cited 5 Sep 2016). https://www. england.nhs.uk/ourwork/pe/mo-dash/

8 Department of Health. Achieving timely "simple" discharge from hospital. London: Department of Health, 2004

9 Bullock S, Morecroft CW, Mullen R, et al. Hospital patient discharge process: an evaluation. Eur J Hosp Pharm 2016. Published Online first: 26 May 2016.

10 Parliamentary and Health Service Ombudsman. A report of investigations into unsafe discharge from hospital. 2016.

11 Care Quality Commission. National NHS patient survey programme National results from the 2014 Inpatient Survey. CQC, 2015.

12 Department of Health. Liberating the NHS: No decision about me without meGovernment response. Department of Health, 2012:39. https://www.gov.uk/ government/uploads/system/uploads/attachment_data/file/216980/Liberatingthe-NHS-No-decision-about-me-without-me-Government-response.pdf

13 Health \& Social Care Joint Unit and Change Agents Team. Discharge from hospital: pathway, process and practice. Department of Health. London: Stationery Office 2003.

14 Katikreddi S, Cloud G. Planning a patient's discharge from hospital. BMJ 2009:338:472-6

15 Carroll A, Dowling M. Discharge planning: communication, education and patient participation. Br J Nurs 2007;16:882-6.

16 Fisher M, Qureshi H, Hardyman W, et al. Social Care Institute for Excellence. Using qualitative research in systematic reviews: older people's views of hospital discharge. How Knowledge Works In Social Care, 2006.

17 Berendsen AJ, de Jong GM, Meyboom-de Jong B, et al. Transition of care: experiences and preferences of patients across the primary/secondary interface-a qualitative study. BMC Health Serv Res 2009;9:62

18 Flink M, Öhlén $G$, Hansagi $H$, et al. Beliefs and experiences can influence patient participation in handover between primary and secondary care-a qualitative study of patient perspectives. BMJ Qual Saf 2012:21(Suppl 1):i76-83.

19 National Institute for Health and Care Excellence (NICE). Medicines optimisation: the safe and effective use of medicines to enable the best possible outcomes. NICE Guideline NG5. London: NICE, 2015.

20 Hesselink G, Flink M, Olsson M, et al. Are patients discharged with care? A qualitative study of perceptions and experiences of patients, family members and care providers. BMJ Qual Saf 2012;21(Suppl 1):i39-49.

21 Krska J, Morecroft CW. Informing patients about medicines-A hospital in-patient survey in England. Patient Educ Couns 2013;90:276-8.

22 Francis R. Report of the Mid Staffordshire NHS Foundation Trust Public Inquiry Executive summary. London, The Stationery Office 2013.

23 Green $C$, Hunter $L$, Jones $L$, et al. The TTO journey: How much of it is actually in pharmacy? Pharm Manag 31;4:16-20.

24 National Institute for Health and Care Excellence. Patient experience in adult NHS services: enabling patients to actively participate in their care. https://pathways.nice. org.uk/pathways/patient-experience-in-adult-nhs-services\#path=view:/pathways/ patient-experience-in-adult-nhs-services/patient-experience-in-adult-nhs-servicesenabling-patients-to-actively-participate-in-their-care.xml\&content=view 